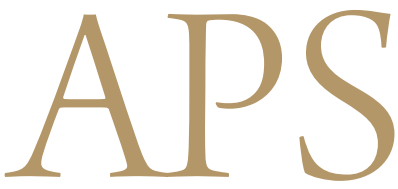

Archives of Plastic Surgery

\title{
A Consideration of Breast Imagery in Art as Depicted through Western Painting
}

\author{
Kun Hwang ${ }^{1}$, Ju Yong Park ${ }^{2}$, Se Won Hwang ${ }^{3,4}$ \\ ${ }^{1}$ Department of Plastic Surgery, Inha University School of Medicine, Incheon; ${ }^{2}$ Inha University School of Medicine, Incheon, Korea; ${ }^{3}$ Peninsula \\ Medical School, Exeter, UK; ${ }^{4}$ Inha Research Institute for Medical Sciences, Incheon, Korea
}

The aim of this study is to consider breast imagery in art as depicted through western painting. Twenty western art paintings were collated. Most of the sample paintings were created from the mid-nineteenth century to the late twentieth century and some are from the Renaissance period. Ten anthropometric items were used to measure 15 distances between two landmarks and 3 angles between three points. The distance from the nipple to the sternal notch and to the midclavicular point was the same and they were 0.46 of the distance from the sternal notch to the umbilicus. The shape of the projection of the breast was almost an isosceles triangle and the altitude of the triangle was at a proportion of 0.45 of the bottom length and 0.16 of the distance from the sternal notch to the umbilicus. The distance between the lateral ends of the breasts was 2.14 times the facial width and the distance between nipples was 1.36 times the facial width. Proportions from works of art are more ideal and attractive than clinically measured proportions. The desirable ratios measured from historical paintings might be useful in planning breast surgeries.

Keywords Breast / Nipples / Paintings

Received: 30 Jul 2014 • Revised: 30 Aug 2014 • Accepted: 1 Sep 2014

pISSN: 2234-6163 • elSSN: 2234-6171 • http://dx.doi.org/10.5999/aps.2015.42.2.226 • Arch Plast Surg 2015;42:226-231
Correspondence: Kun Hwang Department of Plastic Surgery, Inha University School of Medicine, 27 Inhang-ro, Jung-gu, Incheon 400-711, Korea Tel: +82-32-890-3514 Fax: +82-32-890-2918 E-mail: jokerhg@inha.ac.kr

We are grateful to Kwan Hyun Youn, Ph.D., medical illustrator, for the illustrations.

No potential conflict of interest relevant to this article was reported.

\section{INTRODUCTION}

Contemporary concepts of female beauty and femininity necessitate that the breast be esthetically acceptable in all situations of dress and undress [1]. Historically, women have long sought breast enlargements to improve physical proportions, to foster a more feminine appearance, or to enhance one's self-image [2].

By altering a woman's breasts, we, as surgeons, are attempting to balance delicate anatomic and subtle psychological complexities [3].

The aim of this study is to consider breast imagery in art as depicted through western painting.

\section{IDEA}

\section{Sample collection}

Books labeled as 750 (painting \& paintings), 757 (human figures \& their parts), and 759 (historical, areas, persons treatment) of the Dewey Decimal Classification in a certain library, a certain university were searched [4].

While looking through the books, nude paintings, which show the torso from clavicles to the umbilicus were sought. Four nude paintings with the antero-posterior view or a less than 15-degree oblique view were found ('Sacred and Profane Love' by Tizianovecellio [5], 'Maddona' by Edvard Munch [6], 'The Three Graces' by Lucas Cranach [6], and 'Adam and Eve' by Albrecht 
Durer [7].

The name of the above artists was searched via a Google search (www.google.com) and from the images of their painting, 5 websites containing historical descriptions and backgrounds of the paintings were accessed [8-12].

Among the numerous paintings of these websites, 17 paintings of 13 artists were added and a total of 20 western nude paintings (21 torsos since one painting has two torsos) were chosen. Only the paintings having 'beautiful breasts' agreed by at least two authors were included (one of whom was the senior author always in agreement).

Most of the sample paintings were made from mid-nineteenth century to late twentieth century and some are from the Renaissance period (16th century) (Table 1).

According to our previous study, horizontal anthropometric proportions were not significantly different between the anteroposterior view and the less than 15-degree oblique view [13]. Consequently, in this study, paintings of the antero-posterior view or less than 15-degree angled oblique view have been included for measurement.

In 10 paintings among 21 samples of which the lateral view of the breast could be seen, the projections of the breast were measured.

\section{Preliminary study for designations of portraits}

To distinguish oblique paintings under 15-degree, we measured the midclavicle-umblicus-midclavicle (MUM) angle in the photographs of two volunteers wearing five different breast models.

The mean and standard deviation of the MUM angle was $25.50 \pm 3.27$ in the 15 -degree angled view and $20.32 \pm 1.55$ in the 30 -degree angled view. Herein, when the MUM angle was greater than 22.23-degree, we considered the paintings as having less than the 15-degree angle and included them in the samples.

\section{Measuring anthropometric items}

A total of 10 anthropometric items were used to measure 15 distances between two landmarks and 3 angles between three points (Table 2, Fig. 1).

Horizontally, the distance between the lateral ends of the breasts was set as ' $\mathrm{X}$.' Vertically, the distance from the sternal notch to the umbilicus was set as ' $Y$ '.

We calculated two proportions for the torso (Table 2, A, B), 6 proportions for the location of the nipple (Table 2, C-H), 4 proportions for the shape of breast (Table 2, I-L), and 3 angles and 1 projection for the projection of the breast (Table $2, \mathrm{M}-\mathrm{P}$ ).

\section{Measurements}

All 21 samples were obtained from web sites and anthropomet-
Table 1. Art painting list and reference web sites

\begin{tabular}{|c|c|c|c|}
\hline No. & Title of masterpiece & $\begin{array}{c}\text { Completion } \\
\text { date }\end{array}$ & Artist \\
\hline 1 & Sacred and Profane Love [4] & 1514 & Tizianovecellio \\
\hline 2 & Music [9] & 1529 & Hans BaldungGrien \\
\hline 3 & The Three Graces [7] & 1531 & Lucas Cranach \\
\hline 4 & La Scheda di Danae [5] & 1623 & Orazio Gentileschi \\
\hline 5 & $\begin{array}{l}\text { Danae and the Golden } \\
\text { Shower [5] }\end{array}$ & 1750 & Andrea Casali \\
\hline 6 & The Toilet of Esther [7] & 1841 & Theodore Chasseriau \\
\hline 7 & Apollo and Daphne [7] & 1845 & Theodore Chasseriau \\
\hline 8 & Orientalist interior [7] & 1852 & Theodore Chasseriau \\
\hline 9 & The Tepidarium [7] & 1853 & Theodore Chasseriau \\
\hline 10 & The Tepidarium [7] & 1853 & Theodore Chasseriau \\
\hline 11 & Water Nymph [8] & 1856 & $\begin{array}{l}\text { Otto Theodor } \\
\text { GustavLingner }\end{array}$ \\
\hline 12 & A Scultor's Model [7] & 1877 & $\begin{array}{l}\text { Sir Lawrence } \\
\text { Alma-Tadema }\end{array}$ \\
\hline 13 & Diadumene [8] & 1883 & Sir Edward John Poynter \\
\hline 14 & Maddona [10] & 1895 & Edvard Munch \\
\hline 15 & Adam and Eve [6] & 1895 & Albrecht Durer \\
\hline 16 & Seated Bather [7] & 1914 & Pierre Auguste Renoir \\
\hline 17 & Nausicaa [7] & 1937 & William McGregor Paxton \\
\hline 18 & Kimono [8] & 1966 & Catherin Abel \\
\hline 19 & Nu rose [11] & 1995 & Vincent Corpet \\
\hline 20 & Two Friends (Lt.) [8] & Unknown & Anders Leonard Zorn \\
\hline 21 & Two Friends (Rt.) [8] & Unknown & Anders Leonard Zorn \\
\hline
\end{tabular}

1. http://www.artsunlight.com/artist-NT/N-T0001-Titian-Tiziano-Vecellio/N T0001-184-sacred-and-profane-love.html.

2. http://www.thecipher.com/viola_da_gamba_cipher-4.html.

3. http://www.museumsyndicate.com/item.php?item $=10952$.

4. http://www. artsunlight.com/artist-NG/N-G0010-Orazio-Gentileschi/ N-G0010-014-danae.html.

5. http://fineartamerica.com/featured/danae-receiving-the-shower-of-gold-titian.html.

6. http://www.museumsyndicate.com/item.php?item $=33004$.

7. http://www. museumsyndicate.com/item.php?item $=32984$.

8. http://www. museumsyndicate.com/item.php?item $=32992$.

9. http://www.museumsyndicate.com/item. php?item $=33003$.

10. http://fineartamerica.com/featured/standing-female-nude-theodore-chasseriau.html.

11. http://fineartamerica.com/featured/water-nymph-otto-theodor-gustav-lingner.html.

12. http://www.museumsyndicate.com/item.php?item $=14198$.

13. http://fineartamerica.com/featured/diadumene-sir-edward-john-poynter. html.

14. http://www.edvard-munch.com/Paintings/women/madonna_3.jpg.

15. http://www.artsunlight.com/artist-ND/N-D0007-Albrecht-Durer/N-D0007074-adam-and-eve.html.

16. http://www.artsunlight.com/artist-NR/N-R0002-Pierre-Auguste-Renoir/ $\mathrm{N}$-R0002-0518-seated-bather html.

17. http://www. museumsyndicate.com/item.php?item $=10086$.

18. http://fineartamerica.com/featured/kimono-catherine-abel.html.

19. http://www.spectacles-selection.com/archives/expositions/fiche_expo_l/intrusions_petit_palais/intrusions_visuels.htm.

20. http://fineartamerica.com/featured/two-friends-anders-leonard-zorn.html. 21. http://fineartamerica.com/featured/two-friends-anders-leonard-zorn.html.

ric points were measured with the Adobe Photoshop CS2 ver. 9 (Adobe Systems Inc., San Jose, CA, USA) measuring tool. The 10 anthropometric items were measured and 14 proportional indices of the body trunk were calculated. All the values were 
Table 2. The 16 proportions and angles for measuring nipple position and breast shape and projection

\begin{tabular}{|cl|}
\hline No. & \multicolumn{1}{c|}{ Proportion } \\
\hline Proportion of torso & Thoracic width/sternal notch-umbilicus \\
A & Distance between lateral end of breast/sternal \\
B & notch-umbilicus \\
Location of nipple & \\
C & Sternal notch-nipple:nipple-xiphoid:xiphoid-umbilicus \\
D & Distance between nipple/distance between lateral end of \\
E & breast \\
F & Nipple-midclavicular line/distance between lateral end of \\
G & breast \\
H & Sternal notch-nipple/sternal notch-umbilicus \\
Shape of breast & Midclavicle-nipple/sternal notch-umbilicus \\
I & Xiphoid nipple/sternal notch-umbilicus \\
& Upper end of breast-inframammary crease/sternal \\
J & notch-umbilicus \\
K & Ratio between breast width and medial end of \\
L & inframamary fold distance \\
Projection of breast & Facial width/distance between lateral end of breast \\
M & Nipple-perpendicular point/upper end of \\
N & breast-inframammary crease \\
O & Angle of nipple-upper end of breast-perpendicular point \\
P & Angle of upper end of breast-nipple-inframammary crease \\
& Angle of nipple-inframammary crease-perpendicular point \\
\hline
\end{tabular}

obtained in pixels. To avoid inter-personal bias and random systematic error, all measurements and statistical analyses were done by one person.

\section{Results}

\section{Proportion of torso}

A. The thoracic width (tw) was $0.86 \pm 0.12 Y$ (Fig. 2).

B. The distance between the lateral ends of the breasts (bl-bl, X) was $0.85 \pm 0.12 \mathrm{Y}$.

\section{Location of nipple}

C. The ratio of sternal notch-nipple: nipple-xiphoid: xiphoidumbilicus (sn-n:n-xi:xi-um) was approximately 3:2:5 (0.30 \pm $0.08 \mathrm{Y}, 0.21 \pm 0.05 \mathrm{Y}$, and $0.49 \pm 0.08 \mathrm{Y}$, respectively).

$D$. The distance between the nipples $(n-n)$ was $0.63 \pm 0.07 X$.

E. The distance from the nipple to the midclavicular point (n$\mathrm{mc}$ ) was $0.10 \pm 0.03 \mathrm{X}$.

F. The distance from the sternal notch to the nipple (sn-n) was $0.46 \pm 0.13 Y$ (Fig. 2).

$\mathrm{G}$. The distance from the nipple to the midclavicular point (mcn) was $0.46 \pm 0.13 \mathrm{Y}$ (Fig. 2). Herein, the (sn-n) was the same as (mc-n).

$\mathrm{H}$. The distance from the xiphoid process to the nipple (xi-n)

\section{Fig. 1. The distances and the angles for measurement}

The 15 distances and the 3 angles for measuring nipple position, breast shape and projection. bl-bl, distance between the lateral ends of the breasts; tw, thoracic width; $n-n$, distance between nipples; fw, facial width; $n-m c$, distance from the nipple to the midclavicular line; mi-mi, distance between the medial end of the inframammary fold; sn-um, distance from the sternal notch to the umbilicus; sn- $n$, distance from the sternal notch to the nipple; $n-x i$, distance from the nipple to the xiphoid; xi-um, distance from the xiphoid to the umbilicus; up-ic, distance from the upper end of breast to the inframammary crease; mc-n, distance from the midclavicle to the nipple; $s n-n$, distance from the sternal notch to the nipple; $x i-n$, distance from the xiphoid to the nipple; $n$-pp, distance from the nipple to the perpendicular point; $\angle$ nup, angle of the nipple-upper end of the breast-perpendicular point; $\angle$ uni, angle of the upper end of the breast-nipple-inframammary crease; $\angle$ nip, angle of the nipple-inframammary crease-perpendicular point. (A) Frontal view. (B) Projection.
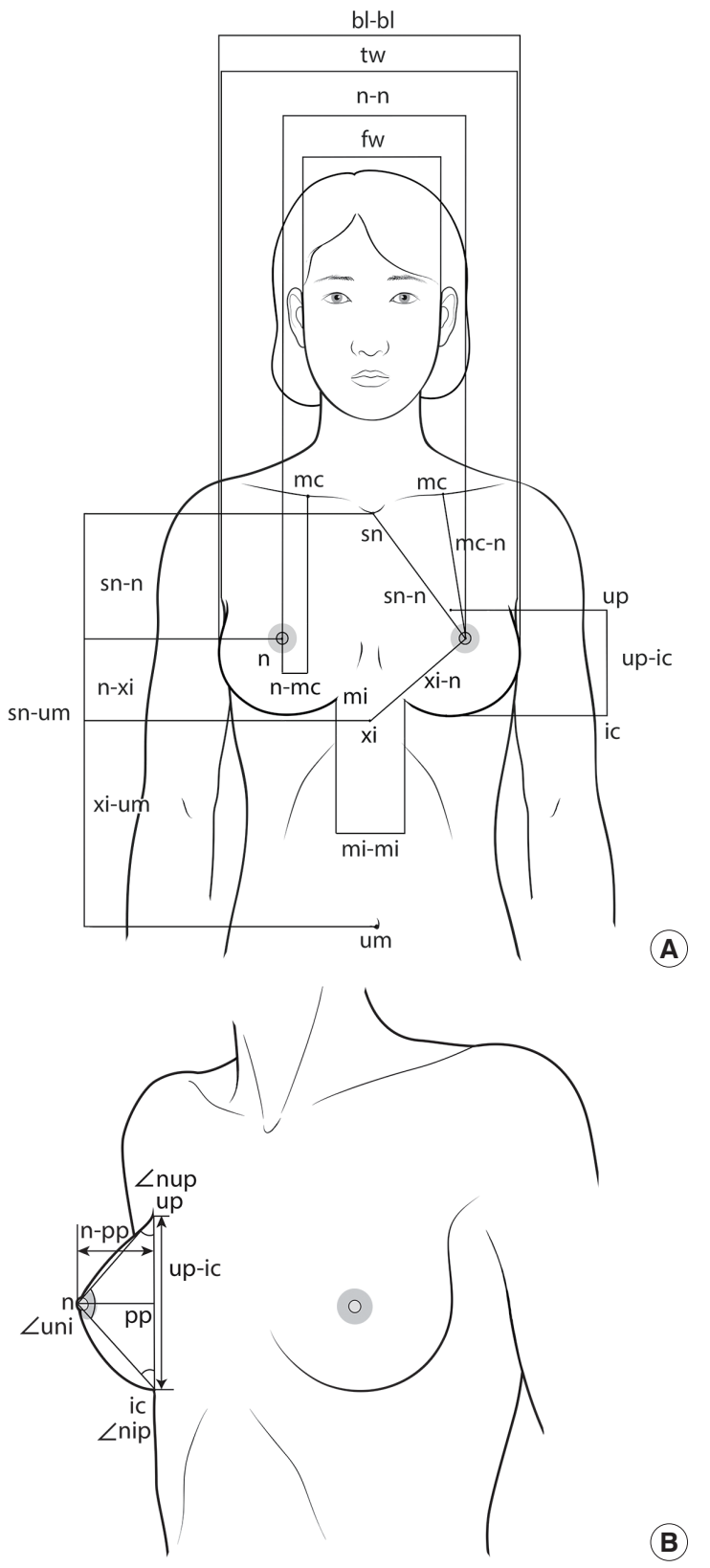


\section{Fig. 2. Vertical and horizontal proportional distances}

$\mathrm{X}$, distance between the lateral ends of the breasts (bl-bl); $n-n$, distance between nipples; fw, facial width; $n-m c$, distance from the nipple to the midclavicular line; $Y$, distance from the sternal notch to the umbilicus (sn-um); xi-um, distance from the xiphoid to the umbilicus; up-ic, distance from the upper end of breast to the inframammary crease.

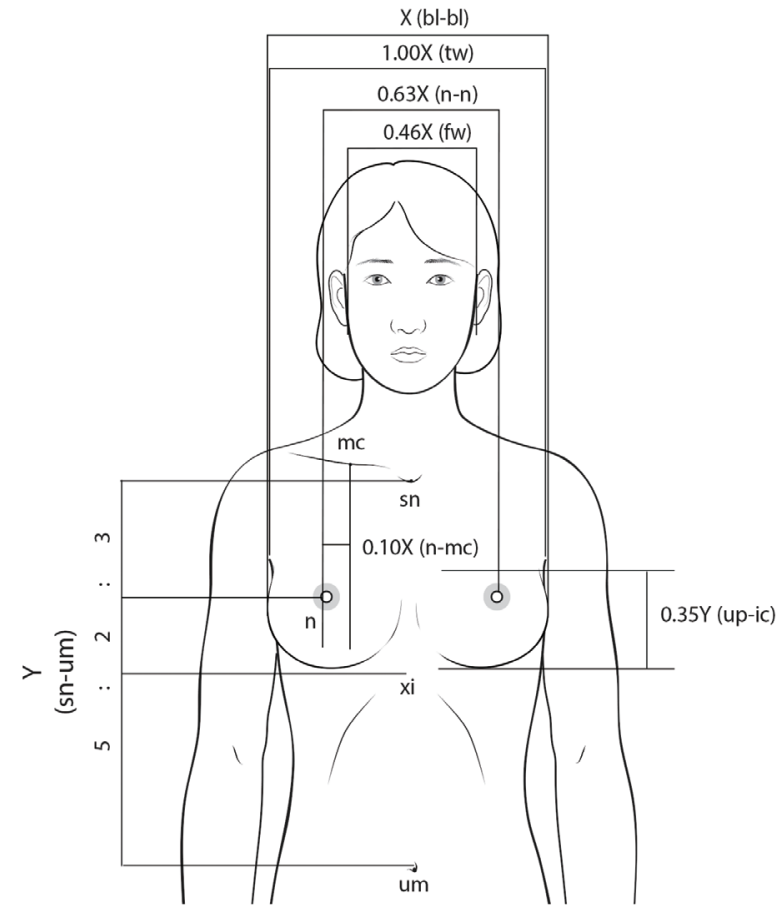

was $0.46 \pm 0.05 \mathrm{X}, 0.39 \pm 0.06 \mathrm{Y}$ (Fig. 2).

\section{Shape of the breast}

I. The distance from the upper end of the breast to the inframammary crease (up-ic) was $0.35 \pm 0.05 Y$.

$\mathrm{J}$. The ratio of breast widths and distance between medial ends of the inframammary fold (bl-mi):(mi-mi):(mi-bl) was approximately 5:3:5 (0.38 $\pm 0.05 \mathrm{X}: 0.23 \pm 0.05 \mathrm{X}: 0.38 \pm 0.05 \mathrm{X})$ (Fig. 3).

$\mathrm{K}$. The tw was the same as between the lateral ends of the breasts (bl-bl, X) (1.00 $\pm 0.08 \mathrm{X})$ (Fig. 2).

L. The facial width $(\mathrm{fw})$ was $0.46 \pm 0.14 \mathrm{X}$. Herein, the distance between the lateral ends of the breasts (bl-bl) was 2.14 times of the facial width ( $\mathrm{fw}$ ) and the distance between the nipples (n-n) was 1.36 times that of the facial width.

\section{Projection of breast}

Shape of the projection of the breast was almost an isosceles triangle.

M. The altitude of the triangle was at a proportion of 0.45 of the bottom length and 0.16 of Y (Fig. 2).

$\mathrm{N}$. Angle of the nipple-upper end of the breast-perpendicular

\section{Fig. 3. Shape of the projection of the breast}

Y, distance from the sternal notch to the umbilicus (sn-um); up-ic, distance from the upper end of breast to the inframammary crease

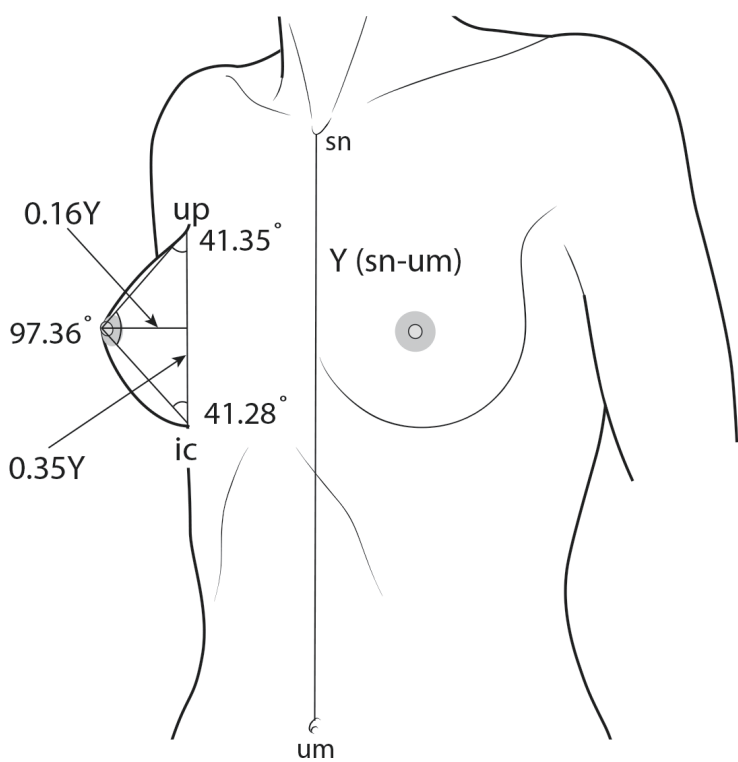

Table 3. Result of nipple position and breast shape and projection

\begin{tabular}{|ll|}
\hline No. & \multicolumn{1}{c|}{ Proportion } \\
\hline Proportion of torso & $0.86 \pm 0.12 Y$ \\
A & $0.85 \pm 0.12 Y$ \\
B & $0.30 \pm 0.08 Y: 0.21 \pm 0.05 Y: 0.49 \pm 0.08 Y$ \\
Location of nipple & $0.63 \pm 0.07 X$ \\
C & $0.10 \pm 0.03 X$ \\
D & $0.46 \pm 0.13 Y$ \\
E & $0.46 \pm 0.13 Y$ \\
F & $0.46 \pm 0.05 X, 0.39 \pm 0.06 Y$ \\
G & \\
H & $0.35 \pm 0.05 Y$ \\
Shape of breast & $0.38 \pm 0.05 X: 0.23 \pm 0.05 X: 0.38 \pm 0.05 X$ \\
I & $1.00 \pm 0.08 X$ \\
J & $0.46 \pm 0.14 X$ \\
K & \\
L & $0.16 \pm 0.04 Y$ \\
Projection of breast & $41.35^{\circ} \pm 4.54^{\circ}$ \\
M & $97.36^{\circ} \pm 6.48^{\circ}$ \\
N & $41.28^{\circ} \pm 3.35^{\circ}$ \\
O & \\
P & \\
\hline X, distance between lateral ends of breast (bl-bl); Y, distance between sternal \\
notch to umbilicus (sn-um); XY (proportion of torso) $=0.85$. \\
\hline
\end{tabular}

point was $41.35 \pm 4.54$ degrees (upper angle).

O. Angle of upper end of the breast-nipple-inframammary crease was $97.36 \pm 6.48$ degrees (middle angle).

P. Angle of the nipple-inframammary crease-perpendicular 


\section{Fig. 4. Breast width and distance}

Result of breast width and distance between the medial ends of the inframammary fold ratio and oblique proportional distances. Y, distance from the sternal notch to the umbilicus (sn-um); mi-mi, distance between the medial end of the inframammary fold; mc-n, distance from the midclavicle to the nipple; sn-n, distance from the sternal notch to the nipple; $x i-n$, distance from the xiphoid to the nipple.

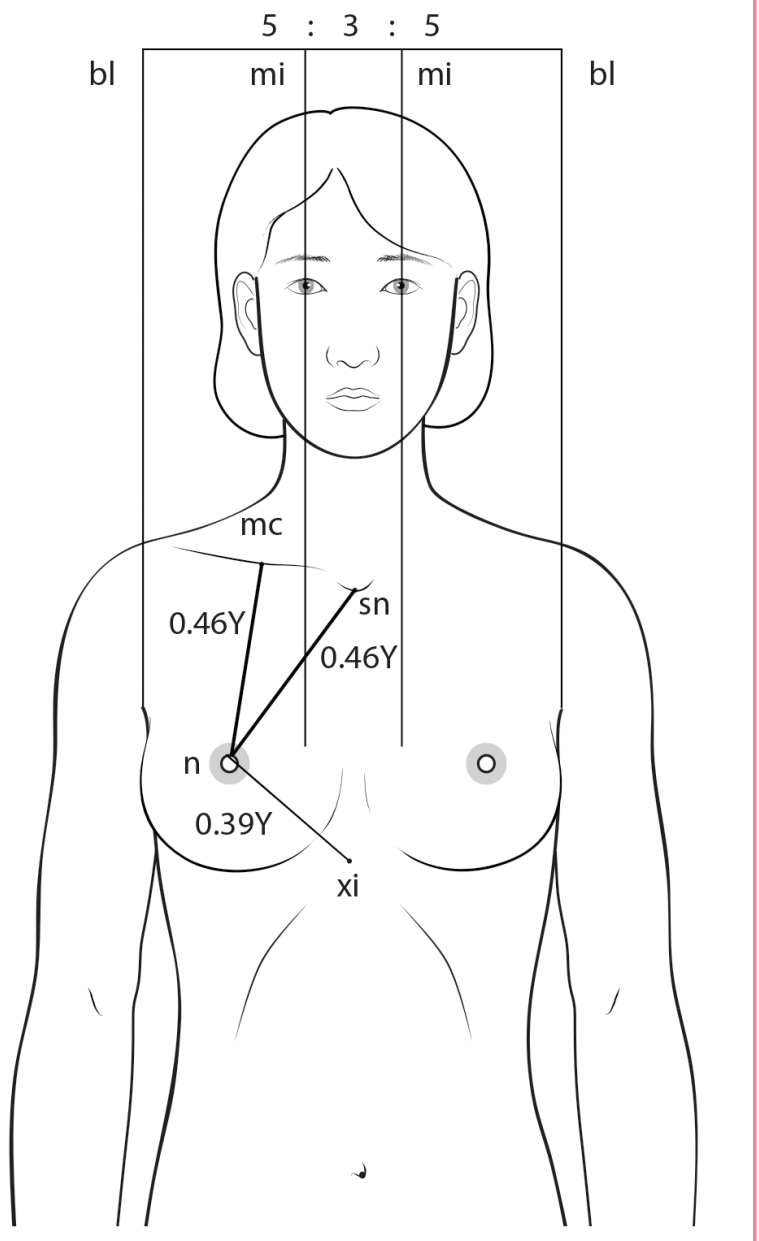

point was $41.28 \pm 3.35$ degrees (lower angle).

Detailed results are shown in Table 3 and Figs. 2-4.

\section{DISCUSSION}

In this study, 21 samples of the antero-posterior view or, less than 15-degree angled oblique view, were included for measurement. In 10 paintings among 21 samples of which the lateral view of the breast could be seen, the projections of the breast were measured. The paintings in which the upper end of breast (up), inframammary crease (ic), and the point from the nipple to the up-ic line (perpendicular point, pp) could be seen, were included.

We had some difficulties in choosing the paintings of antero- posterior view or, less than 15 -degree angled oblique view because these views were rare. Moreover, the anthropometric landmarks were not obvious in some paintings. Many paintings were not 'attractive' or 'beautiful' depending on the evaluators. Only the paintings having 'beautiful breasts' agreed by at least two authors were included (one of whom was the senior author always in agreement).

Regarding the nipple position, Brown et al. [14] stated that the horizontal nipple position was always lateral to the mid-clavicular line by a mean of $25 \mathrm{~mm}$ and the vertical position of the nipple was consistently lower than the mid-humeral line by a mean of $40 \mathrm{~mm}$. The vertical position of the nipple correlated significantly with the lowest point on the inframammary crease [14].

There have been a few anthropometric breast studies. Westreich [15] defined an 'aesthetically perfect breast' as a nonptotic breast in which no common aesthetic procedure would be considered appropriate (excluding augmentation) to enhance the breast's form. The results of the above studies may useful either in planning aesthetic and reconstructive breast surgery or in designing breast augmentation accessories and clothing in certain races. In the above studies, the absolute distances and volumes were measured. Contrarily, we measured and calculated the relative distances from the distance between the lateral ends of the breasts in a horizontal dimension and the distance from the sternal notch to the umbilicus in the vertical dimension.

In our measurements, the distance from the nipple to sternal notch (sn-n) and to the midclavicular point (mc-n) was the same and they were $46 \%$ of the distance from the sternal notch (sn) to the umbilicus (um). The shape of the projection of the breast was almost an isosceles triangle and the altitude of the triangle was at a proportion of 0.45 of the bottom length and 0.16 of the distance from the sternal notch (sn) to the umbilicus (um). The distance between the lateral ends of the breasts (blbl) was 2.14 times of the facial width ( $\mathrm{fw}$ ) and the distance between nipples (n-n) was 1.36 times that of the facial width.

It is noteworthy that the projection of the breast was almost an isosceles triangle and the altitude of the triangle was at a proportion of 0.45 of the bottom length. The distance from the nipple to the sternal notch (sn-n) and to the midclavicular point (mc-n) was the same and this might be applied in a reduction mastectomy or mastopexies.

Expressing a beautiful torso and breasts by drawing nude paintings is subjective and ideal. Proportions from works of art are more ideal and attractive than clinically measured proportions. The desirable ratios measured from historical paintings might be useful in planning breast surgeries including reduction mastectomies or mastopexies. 


\section{REFERENCES}

1. Georgiade NG, Georgiade GS, Riefkohl R. Esthetic breast surgery. In: McCarthy JG, editor. Plastic surgery. Vol. 6. Philadelphia: W.B. Saunders; 1990. p.3839-96.

2. Maxwell GP, Hartley RW. Ch 118. Breast augmentation. In: Mathes SJ, editor. Plastic surgery. Vol 6. Philadelphia: Saunders Elsevier; 2006. p.1-33.

3. Boswick J. Plastic and reconstructive breast surgery. St. Louis, MO: Quality Medical Pub.; 2000.

4. Mitchell JS. Dewey decimal classification and relative index. 23rd ed. Dublin: OCLC Online Computer Library Center, Inc.; 2011.

5. Okada A. Beautiful women in the Renaissance. Seoul: Karam Publishing Co.; 1999.

6. Schneider R. The world's most glamorous woman in the painting 100. Paju (KR): Sogang Publishing Co.; 2009.

7. Arenas A. Why do famous masterpieces? history of Western art to see the masterpieces. Seoul: Davinch Publishing Co.; 2002.

8. Museum syndicate [Internet]. [cited $2013 \mathrm{Feb} 28$ ]. Avail- able from: www.museumsyndicate.com.

9. Fineartamerica [Internet]. Chicago: Fine art America; c2014 [cited 2013 Apr 17]. www.fineartamerica.com assessed on 17 Apr. 2013

10. Cipher [Internet]. U.S. Library of Congress; C2003 [cited 2002 Apr 17]. Available from: www.thecipher.com.

11. ArtSunLight [Internet]. Fujian: ArtSunLight Corporation; [cited $2003 \mathrm{Feb}$ 13]. Available from: www.artsunlight.com.

12. Spectacles selection [Internet]. Paris: Spectacles sélection; [cited 2013 Apr 17]. Available from: www.spectacles-selection.com.

13. Park JY, Hwang SW, Hwang K. Anthropometric comparison of painting portraits of beautiful women, femme fatales, and artists' mothers. J Craniofac Surg 2013;24:2110-4.

14. Brown TP, Ringrose C, Hyland RE, et al. A method of assessing female breast morphometry and its clinical application. Br J Plast Surg 1999;52:355-9.

15. Westreich M. Anthropomorphic breast measurement: protocol and results in 50 women with aesthetically perfect breasts and clinical application. Plast Reconstr Surg 1997; 100:468-79. 